\title{
Structure of the digestive system of ducks depending on sex and genetic background
}

\author{
Rafał Wasilewski ${ }^{1}$, Dariusz Kokoszyński ${ }^{1}$, Anna Mieczkowska ${ }^{1}, Z^{2}$ enon Bernacki ${ }^{1}$, \\ Alina Górska ${ }^{2}$
}
${ }^{1}$ UTP University of Science and Technology, Faculty of Animal Breeding and Biology, Department of Poultry Breeding and Animal Products Evaluation, Bydgoszcz, Poland
${ }^{2}$ Institut of Bioengineering and Animal Breeding, University of Natural Science and Humanities, Siedlce, Poland

Received July 8, 2014

Accepted January 14, 2015

\begin{abstract}
The aim of the study was to determine the effect of genotype and sex on body weight, body dimensions, intestinal length and diameter, percentage of intestinal segments, and weight and percentage of the main internal organs of ducks. The study was performed with 80 Pekin ducks, which were kept throughout rearing (1-49 days of age) in a confinement building and fed commercial waterfowl feed ad libitum. After 7 weeks of rearing, 40 ducks (10 drakes and 10 ducks of hybrid line SM3 Heavy and 10 drakes and 10 ducks of hybrid line AF51) were selected for slaughter. Birds were measured for body length and trunk length. During evisceration, the digestive tract and other internal organs were separated. At 7 weeks of age, SM3 Heavy broilers were heavier and had longer body length and trunk length compared to AF51 ducks. Significant differences were found for body weight in females and for body length in males. The AF 51 females were characterized by significantly greater intestinal length to body length and intestinal length to trunk length ratios, whereas AF51 males showed a greater $(P \leq 0.05)$ body length to trunk length ratio compared to SM3 Heavy birds. Genetic background of the ducks had no significant effect on the length of intestine and its segments, the diameter of different intestinal segments, and the weight and proportion of the gizzard, liver, heart and spleen. The same pattern was observed for the sex of birds except for gizzard weight, which was significantly greater in SM3 Heavy males than females.
\end{abstract}

Duck, genotype, sex, morphometry, digestive tract, internal organs

The digestive system develops at different rates in different poultry species (Lilja 1983). Birds with a higher growth rate are characterized by a more rapid development of the digestive tract. In 7-day-old ducks, the small intestine is $3.7 \times$ heavier and $1.6 \times$ longer than in almost twice lighter turkey poults of the same age (Konarkowski 2006). Over subsequent weeks of life, intestinal length, diameter and surface area of birds increase as does metabolic rate (Lilja 1983; Obst and Diamond 1992). The growth of intestine in birds (intestinal length or intestinal surface area to body weight ratio) is relatively greatest in the first week of life, decreasing with age (Soriano et al. 1993; King et al. 2000). According to Watkins et al. (2004), the morphological and functional growth of the digestive tract in Pekin ducks ceases after 7 weeks of age. Birds show considerable individual variation in the growth of the digestive tract. This is due to many factors, the most important of which include the body size, species, breed, age, sex, and physiological status of the birds. The quantity and quality of ingested food also has a considerable influence (Gille et al. 1999; Szczepańczyk 1999).

The aim of the study was to determine the effect of sex and genetic background of Pekin ducks on body weight and length, trunk length, intestinal structure and dimensions, and proportion ( $\mathrm{g}, \%$ ) of the main internal organs in the body at 7 weeks of age. 


\section{Materials and Methods}

The study was performed with 80 broiler ducks of SM3 Heavy and AF51 hybrids, with 40 birds (20 males and 20 females) per group. The SM3 Heavy hybrids descended from parents imported from Cherry Valley Farms Ltd. from England, whereas the AF51 ducks are two-strain crosses created in Poland (A55 males ' F11 females). Throughout rearing (1 to 49 days of age) the birds were kept on litter in a closed building under controlled environment in 8 pens (10 birds per pen), each having an area of $12 \mathrm{~m}^{2}$. During the first weeks of growth, a local source of heat and light (infrared heaters) was used. Ventilation and air movement were adjusted to the birds' age. The experiment was approved by the Local Ethics Committee for Experiments with Animals in Bydgoszcz (Experiment No. 27/2012).

The ducks were fed ad libitum commercial waterfowl feed manufactured by Cargill Poland Sp. $\mathrm{z}$ o.o. in Warsaw, Świecie branch (Poland). From weeks 1 to 3 inclusive, the birds received a diet containing $21.5 \%$ crude protein, $11.8 \mathrm{MJ}$ metabolizable energy, $2.8 \%$ crude fibre, $4.7 \%$ crude fat, and $4.9 \%$ crude ash. From weeks 4 to 7 , the birds were fed a diet containing $18.6 \%$ crude protein, $12.1 \mathrm{MJ}$ metabolizable energy, $3.9 \%$ crude fibre, $4.4 \%$ crude fat, and $4.3 \%$ crude ash. Chemical analyses of the feed mixtures were performed at the laboratory of the Department of Animal Nutrition and Feed Management Economy belonging to the UTP University of Science and Technology in Bydgoszcz. The energy content was calculated from the energy value of the components. Throughout the rearing period, the ducks had 24-hour access to fresh drinking water.

At 7 weeks of age, the ducks were individually weighed on electronic scales for weighing poultry (WGJ-R, JOTAFAN, Kraków, Poland) accurate to $1 \mathrm{~g}$. After determining their body weights, 40 birds (20 males and 20 females) whose body weights were similar to the group mean for given sex were selected for slaughter and their body dimensions were tape-measured to the nearest $1 \mathrm{~mm}$ for body length between the first cervical vertebra and the posterior superior tuberosity of the ischium, and for trunk length between the shoulder joint and the posterior superior tuberosity of the ischium.

The body measurements were followed by slaughter, defeathering and evisceration of the ducks. The evisceration included separation of the intestine. The lengths of the duodenum, jejunum, ileum, two caeca and colon were tape-measured to the nearest $1 \mathrm{~mm}$. The proportion of intestinal segments was expressed as percentage in relation to the total intestinal length. Electronic calipers were used to determine the diameter of these intestinal segments to the nearest $0.01 \mathrm{~mm}$. The diameter was measured in the upper, middle and lower parts of the intestinal segments. The intestinal length to body length and the intestinal length to trunk length ratios were also calculated.

The following organs were also separated and weighed to the nearest $0.001 \mathrm{~g}$ on an electronic scale (M160, Medicat, Zurich, Switzerland): gizzard, proventriculus, liver, heart, and spleen. Afterwards their proportion (\%) in the body weight of the ducks selected for slaughter was calculated.

The numerical data were analysed statistically using the SAS/STAT version 9.1 software. Arithmetic means and standard deviation (mean $\pm \mathrm{SD}$ ) were calculated for the studied traits. Significant differences between the mean values of the analysed traits were verified with a Tukey's pair-wise comparison test. Differences were considered significant at $P<0.05$.

\section{Results}

At 7 weeks of age, SM3 Heavy males and females were heavier and had longer body length and trunk length compared to AF51 birds. Significant differences were found for body weight in females and for body length in males, which was greater in SM3 Heavy ducks. No significant differences were observed in these traits between males and females (Table 1). SM3 Heavy broilers had a shorter $(P>0.05)$ intestine and significantly lower intestinal length to trunk length ratios compared to AF51 birds. In addition, SM3 Heavy females had significantly lower intestinal length to body length ratios compared to AF51 ducks. Compared to females, males were characterized by nonsignificantly greater intestinal length and intestinal length to body length ratio in both hybrid groups under comparison. In SM3 Heavy ducks, the intestinal length to trunk length ratio was greater in females than in males, and the reverse situation occurred for AF51 birds $(P>0.05)$ (Table 1). Both genotypes compared were commercial hybrids of Pekin ducks intended for broiler production. The SM3 Heavy hybrids were heavy Pekins (with greater body weight), whereas AF51 ducks are medium heavy birds.

The genotype and sex of the studied ducks had no significant effect on the lengths of different intestinal segments. The SM3 Heavy males had shorter jejunum, ileum and colon, and longer duodenum and caecum compared to AF51 males. In females, all the intestinal segments were longer in AF51 birds (Table 2). 
Table 1. Body weight, body length, trunk length, intestinal length, intestinal length to body length, and intestinal length to trunk length ratios in 7-week-old Pekin ducks $(\mathrm{x} \pm \mathrm{SD})$.

\begin{tabular}{lcccc}
\hline & \multicolumn{3}{c}{ Genotype - sex } \\
\cline { 2 - 5 } Trait & \multicolumn{2}{c}{ SM3 Heavy } & Females & Males \\
\cline { 2 - 5 } & $2857.20 \pm 50.05^{\mathrm{a}}$ & $2952.20 \pm 112.31^{\mathrm{a}}$ & $2566.00 \pm 94.48^{\mathrm{b}}$ & $2827.00 \pm 109.32^{\mathrm{a}}$ \\
\cline { 2 - 5 } Body weight (g) & $43.70 \pm 2.28^{\mathrm{a}}$ & $45.90 \pm 0.54^{\mathrm{a}}$ & $42.20 \pm 1.09^{\mathrm{a}}$ & $42.70 \pm 1.15^{\mathrm{b}}$ \\
Body length (cm) & $27.80 \pm 1.15^{\mathrm{a}}$ & $29.90 \pm 1.14^{\mathrm{a}}$ & $27.40 \pm 0.65^{\mathrm{a}}$ & $27.80 \pm 0.97^{\mathrm{a}}$ \\
Trunk length (cm) & $248.10 \pm 21.70^{\mathrm{a}}$ & $263.60 \pm 22.92^{\mathrm{a}}$ & $262.40 \pm 5.01^{\mathrm{a}}$ & $267.30 \pm 7.74^{\mathrm{a}}$ \\
Intestinal length (cm) & & & $6.26 \pm 0.24^{\mathrm{a}}$ \\
Intestinal length to body & $5.67 \pm 0.51^{\mathrm{a}}$ & $5.74 \pm 0.54^{\mathrm{a}}$ & $6.22 \pm 0.23^{\mathrm{b}}$ & $6.26 \pm 0.22^{\mathrm{b}}$ \\
length ratio & & & & $9.58 \pm 0.38^{\mathrm{b}}$ \\
Intestinal length to trunk & $8.92 \pm 0.97^{\mathrm{a}}$ & $8.82 \pm 0.59^{\mathrm{a}}$ & $9.61 \pm 0.05)$ \\
length ratio & & &
\end{tabular}

$\mathrm{a}, \mathrm{b}-$ means of traits in rows within sexes, marked with different letters differ significantly $(P \leq 0.05)$

Table 2. Length of intestinal segments in 7-week-old Pekin ducks ( $\mathrm{x} \pm \mathrm{SD})$.

\begin{tabular}{lllll}
\hline \multirow{2}{*}{ Trait } & \multicolumn{4}{c}{ Genotype - sex } \\
\cline { 2 - 5 } & \multicolumn{2}{c}{ SM3 Heavy } & Females & AF51 \\
\cline { 2 - 5 } & \multicolumn{1}{c}{ Females } & Males & $32.80 \pm 3.15$ & $32.40 \pm 3.57$ \\
\hline Duodenum (cm) & $31.60 \pm 5.48$ & $34.00 \pm 3.85$ & $91.40 \pm 1.82$ & $94.80 \pm 2.94$ \\
Jejunum (cm) & $87.40 \pm 7.30$ & $92.30 \pm 11.47$ & $87.50 \pm 3.96$ & $91.60 \pm 2.54$ \\
Ileum (cm) & $82.80 \pm 10.08$ & $89.90 \pm 10.50$ & $37.40 \pm 3.43$ & $36.40 \pm 1.81$ \\
Caecum (cm) & $36.00 \pm 2.91$ & $37.20 \pm 1.92$ & $13.30 \pm 2.13$ & $12.10 \pm 1.02$ \\
Colon $(\mathrm{cm})$ & $10.30 \pm 1.64$ & $10.20 \pm 1.48$ & & \\
\hline
\end{tabular}

Table 3. Diameter of intestinal segments in 7-week-old Pekin ducks ( $x \pm \mathrm{SD})$.

\begin{tabular}{lcccc}
\hline \multirow{2}{*}{ Trait } & \multicolumn{4}{c}{ Genotype - sex } \\
\cline { 2 - 5 } & \multicolumn{2}{c}{ SM3 Heavy } & Females & MF51 \\
\cline { 2 - 5 } & \multicolumn{1}{c}{ Females } & Males & $7.79 \pm 1.18$ & $8.22 \pm 0.88$ \\
\cline { 2 - 5 } Duodenum (mm) & $8.84 \pm 1.06$ & $9.27 \pm 1.49$ & $6.82 \pm 0.93$ & $7.17 \pm 0.73$ \\
Jejunum (mm) & $7.53 \pm 0.64$ & $7.64 \pm 0.99$ & $7.30 \pm 0.56$ & $7.35 \pm 0.91$ \\
Ileum (mm) & $8.08 \pm 1.89$ & $6.61 \pm 0.69$ & $6.93 \pm 0.84$ & $6.59 \pm 1.07$ \\
Caecum (mm) & $7.66 \pm 0.74$ & $6.83 \pm 1.46$ & $10.92 \pm 0.80$ & $9.87 \pm 1.01$ \\
Colon (mm) & $11.08 \pm 2.49$ & $10.76 \pm 1.16$ & \\
\hline
\end{tabular}

No significant differences due to sex and genetic background of the ducks were observed in the diameter of different intestinal segments (Table 3). In both groups, the largest diameter was characteristic of the colon, followed by the duodenum. Individual intestinal segments of SM3 Heavy males and females had a larger diameter compared to those of AF51 birds except for ileum in females.

The analysed groups of ducks did not differ significantly in the percentage length of different intestinal segments (Table 4). Regardless of sex and genetic background, the largest percentage in the total intestinal length was observed for the jejunum, followed by the ileum, caecum, duodenum and colon. The small intestine (duodenum, jejunum, ileum) constituted over $80 \%$ of intestinal length, caeca from 13.62 (AF51 males) to $14.51 \%$ (SM3 Heavy females), and colon from 3.88 (SM3 Heavy males) to 5.07\% (AF51 females). 
Table 4. Percentage of the length of intestinal segments in 7-week-old Pekin ducks ( $x \pm \mathrm{SD})$.

\begin{tabular}{|c|c|c|c|c|}
\hline \multirow{3}{*}{ Trait } & \multicolumn{4}{|c|}{ Genotype - sex } \\
\hline & \multicolumn{2}{|c|}{ SM3 Heavy } & \multicolumn{2}{|c|}{ AF51 } \\
\hline & Females & Males & Females & Males \\
\hline Duodenum (\%) & $12.74 \pm 1.06$ & $12.89 \pm 1.04$ & $12.50 \pm 1.24$ & $12.12 \pm 1.45$ \\
\hline Jejunum (\%) & $35.22 \pm 0.75$ & $35.02 \pm 1.12$ & $34.83 \pm 1.65$ & $35.46 \pm 1.59$ \\
\hline Ileum (\%) & $33.37 \pm 1.04$ & $34.10 \pm 0.83$ & $33.35 \pm 2.82$ & $34.27 \pm 1.17$ \\
\hline Caecum (\%) & $14.51 \pm 1.36$ & $14.11 \pm 0.87$ & $14.25 \pm 0.67$ & $13.62 \pm 1.04$ \\
\hline Colon (\%) & $4.16 \pm 0.84$ & $3.88 \pm 0.32$ & $5.07 \pm 0.63$ & $4.53 \pm 0.42$ \\
\hline
\end{tabular}

Analysis of the data presented in Table 5 indicates that duck genotype had no significant effect on the weight of the main internal organs. A significant effect of sex was only found for the weight of gizzard in SM3 Heavy ducks, which was heavier $(P \leq 0.05)$ in males. Compared to AF51 drakes, SM3 Heavy males had heavier gizzard and liver, and lighter proventriculus, heart, and spleen. The weight of different internal organs in SM3 Heavy females was lower than in AF51 females except for liver weight.

The percentage of the main internal organs in the body of the ducks evaluated at 7 weeks of age was similar, with no significant differences (Table 6). Gizzard and liver percentage was the highest in SM3 Heavy males, and proventriculus and heart percentage in AF51 drakes. Gizzard percentage was the lowest in SM3 Heavy females, liver percentage in AF51 females, and heart and spleen percentage in SM3 Heavy birds.

Table 5. The weight of the main internal organs in 7-week-old Pekin ducks ( $x \pm \mathrm{SD})$.

\begin{tabular}{lrrrr}
\hline \multirow{2}{*}{ Trait } & \multicolumn{4}{c}{ Genotype - sex } \\
\cline { 2 - 5 } & \multicolumn{2}{c}{ SM3 Heavy } & \multicolumn{1}{c}{ Females } & Males \\
\cline { 2 - 5 } & \multicolumn{1}{c}{ Females } & Males & $83.51 \pm 8.62^{\mathrm{a}}$ & $90.00 \pm 9.00^{\mathrm{a}}$ \\
Gizzard (g) & $86.90 \pm 7.11^{\mathrm{a}}$ & $98.50 \pm 6.40^{\mathrm{b}}$ & $6.96 \pm 1.17^{\mathrm{a}}$ & $8.92 \pm 1.96^{\mathrm{a}}$ \\
Proventriculus (g) & $7.64 \pm 0.89^{\mathrm{a}}$ & $8.82 \pm 1.66^{\mathrm{a}}$ & $39.12 \pm 3.12^{\mathrm{a}}$ & $43.40 \pm 2.50^{\mathrm{a}}$ \\
Liver (g) & $44.22 \pm 4.40^{\mathrm{a}}$ & $49.80 \pm 5.20^{\mathrm{a}}$ & $13.60 \pm 0.92^{\mathrm{a}}$ & $15.13 \pm 1.60^{\mathrm{a}}$ \\
Heart (g) & $13.61 \pm 1.60^{\mathrm{a}}$ & $14.20 \pm 1.90^{\mathrm{a}}$ & $1.70 \pm 0.27^{\mathrm{a}}$ & $1.98 \pm 0.55^{\mathrm{a}}$ \\
Spleen (g) & $1.64 \pm 0.18^{\mathrm{a}}$ & $1.64 \pm 0.37^{\mathrm{a}}$ & &
\end{tabular}

a, b - means of traits in rows between sexes within genetic group, marked with different letters differ significantly $(P \leq 0.05)$

Table 6. Percentage of the main internal organs in 7-week-old Pekin ducks $(x \pm S D)$.

\begin{tabular}{lcccc}
\hline \multirow{2}{*}{ Trait } & \multicolumn{4}{c}{ Genotype - sex } \\
\cline { 2 - 5 } & \multicolumn{2}{c}{ SM3 Heavy } & Females & AF51 \\
\cline { 2 - 5 } & Females & Males & $3.25 \pm 0.50$ & $3.18 \pm 0.20$ \\
Gizzard (\%) & $3.04 \pm 0.21$ & $3.34 \pm 0.12$ & $0.27 \pm 0.05$ & $0.32 \pm 0.09$ \\
Proventriculus (\%) & $0.27 \pm 0.03$ & $0.29 \pm 0.05$ & $1.52 \pm 0.09$ & $1.54 \pm 0.11$ \\
Liver (\%) & $1.55 \pm 0.23$ & $1.68 \pm 0.10$ & $0.53 \pm 0.03$ & $0.54 \pm 0.05$ \\
Heart (\%) & $0.48 \pm 0.04$ & $0.48 \pm 0.06$ & $0.07 \pm 0.01$ & $0.07 \pm 0.01$ \\
Spleen (\%) & $0.06 \pm 0.01$ & $0.06 \pm 0.01$ & & \\
\hline
\end{tabular}




\section{Discussion}

The mean body weight of the 7-week-old broiler ducks was rather high, which may be indicative of their normal growth. In another study (Bernacki et al. 2008), 7-week-old Pekin PP54 ducks had a similar body weight (males 2 954, females 2694 g), and Star 63 ducks a higher body weight (males $3302 \mathrm{~g}$, females $2913 \mathrm{~g}$ ) compared to the ducks under study. In a study by Biesiada-Drzazga et al. (2011), the mean body weight of Star 53 HY ducks aged 7 weeks was $2996.2 \mathrm{~g}$ in males and $2397.5 \mathrm{~g}$ in females. Even smaller body weights in two-strain Pekin crosses were reported by Górska et al. (2014). The evaluated ducks had shorter body, but longer trunk compared to the 7-week-old P44 and P55 ducks investigated by Kokoszyński and Bernacki (2011).

Earlier studies with Pekin ducks (King et al. 2000; Jamroz et al. 2001) reported smaller lengths of different intestinal segments compared to the analysed ducks of the same age. The evaluated ducks did not differ in morphometric characteristics of the intestine and other internal organs, which is in contradiction with the results of Downing (2010). When investigating the growth of Cherry Valley and Grimaund Fréres ducks until 6 weeks of age under summer conditions, Downing (2010) showed that strain (A, B, AB and BA) had a significant effect on liver weight to liveweight \% (weeks 1 and 5), whereas sex had a significant effect on the relative length $(\mathrm{cm} / 100 \mathrm{~g}$ liveweight $)$ of the duodenum. In an experiment conducted in winter, the same author showed significant differences between ducks of different genotypes in relative length of the duodenum and ileum (weeks 2, 4 and 5 ) as well as the effect of sex on the percentage of proventriculus (week 6) and gizzard (weeks 4, 5 and 6) and on the relative length of the duodenum (weeks 5 and 6). The SM3 Heavy and AF51 birds evaluated at 7 weeks of age had similar gizzard weight, lower liver weight, heart weight and gizzard percentage, and higher liver percentage compared to ducks of the same age studied by Kokoszyński (2011). Downing (2010) found a greater liver percentage compared to the evaluated ducks and a significantly greater liver and gizzard percentage in drakes compared to ducks.

In summary, compared to AF51 birds, SM3 Heavy ducks were characterized by greater body weight, longer body and trunk, and greater gizzard and liver weight. AF51 ducks had longer intestine and higher intestinal length to body length and higher intestinal length to trunk length ratios compared to SM3 Heavy birds. The sex of birds had no significant effect on the analysed traits except for gizzard weight.

\section{References}

Bernacki Z, Kokoszyński D, Mallek T 2008: Evaluation of selected meat traits in seven-week-old duck broilers. Anim Sci Pap Rep 26: 165-174

Biesiada-Drzazga B, Charuta A, Janocha A, Lęczycka J 2011: Assessment of slaughter value Pekin ducks STAR 53 HY. Rocz Nauk PTZ 7: 109-116

Downing JA 2010: Commercial duck production for bird welfare, environmental benefits and efficiency. RIRDC, Barton (Australia), 209 p.

Górska A, Górski J, Mróz E 2014: Effect of inter-strain crossbreeding in diallele design (4×4) on growth, weight of carcass and weight of basic group of muscle in Pekin duck crossbreds. Europ Poult Sci 78: DOI: 10.1399/ eps. 2014.7

Gille U, Salomon FV, Rönnert J 1999: Growth of digestive organs in ducks with considerations on their growth in birds in general. Br Poult Sci 40: 194-202

Jamroz D, Jakobsen K, Orda J, Skorupińska J, Wiliczkiewicz A 2001: Development of the gastrointestinal tract and digestibility of dietary fibre and amino acids in young chickens, ducks and geese fed diets with high amounts of barley. Com Bioch Physiol A130: 643-652

King D, Asem E, Adeola O 2000: Ontogenetic development of intestinal digestive functions in white Pekin ducks. J Nutr 130: 57-62

Kokoszyński D 2011: Evaluation of meat traits in commercial crossbreds of Pekin type ducks. UTP Bydgoszcz, 113 p.

Kokoszyński D, Bernacki Z 2011: Comparison of meat performance of Pekin ducks from two conservative flocks. J Cent Eur Agric 9: 215-225 
Konarkowski A 2006: Development of small intestine in chicks: Polish Poultry 7: 21-23

Lilja C 1983: A comparative study of postnatal growth and organ development in some species of birds. Growth 47: $317-339$

Obst BS, Diamond JM 1992: Ontogenesis of intestinal nutrient transport in domestic chickens (Gallus gallus) and its relation to growth. Auk 109: 451-464

SAS Institute Inc. 2010: SAS/STAT User's guide, ver. 9.1. Cary, NC: SAS institute Inc.

Soriano ME, Rovira N, Pedros N, Planas JM 1993: Morphometric changes in chicken small intestine during development. Z Gastroenterol 31: 578 (abs)

Szczepańczyk E 1999: Morphometry and morphology of alimentary tract of Red-necked Grebe. Appl Sci Rep 45: 99-109

Watkins E, Butler P, Kenyon B 2004: Posthatch growth of the digestive system in wild and domesticated ducks. Br Poult Sci 45: 331-341 